\title{
TRANSFORMASI PANGURASON DARI RITUAL KE SENI PERTUNJUKAN
}

\author{
${ }^{1}$ Sivalis Diana Sari, ${ }^{2}$ Nurwani \\ Prodi Pendidikan Tari/ Fakultas Bahasa dan Seni/ Universitas Negeri Medan \\ Jalan Willem Iskandar Pasar V Medan Estate 20221, Sumatera Utara-Indonesia \\ sivalisdianasari@gmail.com, Nurwanipilago@gmail.com
}

\begin{abstract}
This study discusses the Transformation of Pangurason Performing Arts Ritual. Describes the presentation of Pangurason tortors in the transformation of saucers to the Batak Toba Society in Samosir, and also describes the transformation of Pangurason tortors in the art of tortor cup performances.The theory used in this research is Ritual theory, Transformation, presentation theory form. The time used in this study is during (two months), which starts from October to December 2016. The location of this study was conducted in Pangururan Government of Samosir Regency. The population in this study were artists who knew about Pangurason and the samples were all actors involved in tortor Pangurason and actors involved in tortor bow transformation, data collection techniques including observation, interview, literature study, and documentation, then analyzed by descriptive method qualitative.Based on the data collected, it can be seen that Pangurason is a cleansing or purification of a place that has been considered sacred, so that the place is far from distress, and not disturbed by evil spirits. Formerly when Pangurason was used because at that time, the place wanted to be disturbed by evil spirits, then sibaso or shaman made a ritual to reject the reinforcements, by making a bowl of water, kaffir lime and banyan leaves.

The transformation transforms the form of ritual presentation into the performing arts and uses the media or property of the saucer as an attraction in the tortor cup art show.
\end{abstract}

Keywords: Transformation, Pangurason Ritual, Performing Arts

\section{PENDAHULUAN}

Sumatera Utara adalah salah satu Provinsi yang terletak di Negara Indonesia. Sumatera Utara memiliki keanekaragaman suku dan budaya. Suku asli di daerah Sumatera Utara ada 8 yaitu: Simalungun, Mandailing, Melayu, Pesisir Sibolga, Pak-pak, Karo, Nias dan Batak Toba. Setiap suku tersebut memiliki budaya yang berbeda-beda, hal ini disebabkan karena setiap suku mempunyai pandangan hidup, cara mengekspresikan diri dan kebiasaan hidup yang berbeda.

Orang Batak dewasa ini sebagian besar mendiami daerah pegunungan Sumatera Utara, mulai dari perbatasan daerah Istimewa Aceh di
Utara sampai keperbatasan dengan Riau dan Sumatera Barat disebelah selatan. Selain itu, orang Batak juga mendiami tanah datar yang berada diantara daerah pegunungan dengan pantai Timur Sumatera Utara dan pantai Barat Sumatera Utara. Dengan demikian, maka orang batak ini mendiami dataran tinggi Karo, Langkat Hulu, Simalungun, Dairi, Toba, Humbang Hasudutan, Silindung, Angkola, Mandailing dan Kabupaten Tapanuli Tengah Bangun (1980:94).

Masyarakat Batak Toba mengenal berbagai macam bentuk kesenian tradisional yang sudah hidup sejak dahulu kala dan dilestarikan oleh anak cucu (masyarakat mereka hingga kini). Adapun jenis-jenis kesenian orang Batak Toba; 
seni tari, seni musik, seni rupa, seni sastra, seni drama. Seni dan Budaya merupakan suatu hal yang tidak bisa dilepaskan dari kehidupan Masyarakat Batak Toba, salah satunya seperti tarian-tarian atau tortor yang diiringi musik gondang. Secara umum tari pada masyarakat Batak Toba merupakan suatu kontek yang tidak bisa lepas dari kehidupan masyarakat Batak Toba. Tarian dari suku Batak Toba adalah Tortor hadir disegala kegiatan ritual, adat dan acara sakral lainnya di tengah-tengah masyarakat Batak Toba.

Menurut kepercayaan masyarakat Batak Toba, Pangurason hadir disebabkan karena manusia melanggaradat istiadat yang ada dibumi. Sehingga yang kuasa menurunkan tujuh bidadari untuk membersihkan alam atau wilayah yang mereka tempati, untuk menguras atau membersihkan bumi. Ritual pangurason ditarikan oleh tujuh wanita, dimana masing-masing membawa satu buah cawan. Salah satu diantara mereka memimpin doa untuk membersihkan alam, yang disebut dengan sibaso.

Dalam ritual pangurason terdapat gerakan seperti somba adat dan somba debata, gerakan memercikkan air yang terdapat didalam cawan sebagai media upacara. Air tersebut dipercaya sebagai media pembersihan alam, yang disebut dengan pangurason dan ini biasanya digelar pada saat acara besar. Sebelum acara dimulai, tempat dan lokasi acara dibersihkan oleh sibaso dengan menggunakan air yang berisi jeruk purut, agar jauh dari mara bahaya. Datu (orang yang tertua) menjemput sibaso, kemudian menggelilingi sibaso dengan maksud membujuk, agar sibaso dapat membersihkan tempat tersebut dengan melakukan pangurason. Raja beserta datu manortor dan membawa sibaso ketengah halaman, dimana tempat tersebut akan dibersihkan dan disucikan. Raja memberikan cawan yang berisi air, jeruk purut, dan daun beringin kepada datu. Kemudian Datu memberikan kepada Sibaso untuk didoakan. Setelah didoakan, air pangurason dipercikan oleh Sibaso ke delapan penjuru mata angin atau disebut dengan "Desa Naalu".

Dengan masuknya agama kristen pada tahun 1820, maka ritual pangurason mulai hilang. Setelah Nommensen berhasil menyebarkan kitab injil sehingga masyarakat Batak Toba banyak yang menganut agama Kristen, ritual itu mulai terkikis dan hampir tidak ada lagi sampai saat ini karena dianggap ritual itu tidak sesuai dengan kepercayaan agama Kristen yang disebut juga dengan Syirik.

Pada tahun 1953 pangurason mulai muncul kembali dalam bentuk seni pertunjukan, yang diangkat oleh Sitangsi Boru Simbolon. Dialah orang yang pertama sekali menciptakan tari pangurason dengan tujuh sawan. Dulunya pada ritual pangurason hanya menggunakan satu sawan sebagai media untuk meletakkan air pangurason. Setelah mengalami pergeseran, tari pangurason sudah menggunakan lebih dari satu sawan seperti tiga, lima, tujuh. Kemudian tari ini dapat dilihat dari kemampuan penari membawa sawan dengan unsur akrobatik.

Di lihat dari fenomena yang terdapat pada ritual pangurason yang sudah 
bertransformasi menjadi seni pertunjukan, maka penulis tertarik untuk mengangkat menjadi penelitian yang berjudul "Transformasi Pangurason Dari Ritual Keseni Pertunjukan".

Untuk meneliti dan membahas tentang transformasi Pangurason dari ritual ke seni pertunjukan, maka penulis menggunakan tiga teori yaitu: teori ritual, teori seni pertunjukan, dan teori transformasi. Teori ritual yang digunakan adalah teori ritual menurut Y. Sumandiyo Hadi (1999:29-30), "Ritual merupakan suatu bentuk upacara atau perayaan (celebration) yang berhubungan denga beberapa kepercayaan agama yang ditandai oleh sifat khusus, yang menimbulkan rasa hormat yang luhur dalam arti suatu pengalaman yang suci”. Teori seni pertunjukan yang digunakan adalah teori seni pertunjukan menurut Taufik Rahzen (1997), "Seni pertunjukan adalah karya seni yang melibatkan aksi individu atau kelompok di tempat tertentu".Dan teori transformasi yang digunakan adalah teori transformasi menurut $\mathrm{Y}$. Sumandiyo Hadi.

Penelitian ini dilaksanakan dua kali. Sesuai dengan judul penelitian (Transformasi Pangurason Dari Ritual ke Seni Pertunjukan) maka penelitian dilaksanakan di Pangururan Kabupaten Samosir pada 24 Oktober 2017 - 10 Desember 2017; dan penelitian kedua dilaksanan di Sanggar Ruma Aksara Aswan Togi Sirait pada 15 Februari 2018 - 5 April 2018. Penguatan populasi dalam penelitian ini adalah budayawan Batak Toba, seniman, penari dan masyarakat yang mengerti dan paham tentang ritual pangurason. Kemudian untuk mendapatkan sampel dalam penelitian ini adalah seluruh penari dalam pangurason, seniman, tokoh masyarakat dan masyarakat Batak Toba.

Metode yang digunakan dalam pelaksanaan penelitian ini adalah metode kualitatif deskriptif. Teknik pengumpulan data yang dilakukan adalah sebagai berikut: 1). Studi Pustaka, 2). Observasi, 3). Wawancara, 4). Dokumentasi.

Dalam penelitian ini setelah data terkumpul, keseluruhan data dikelompokkan sesuai dengan permasalahan yang diangkat, setelah itu menganalisis secara sistematis dengan menggunakan metode strategi analisis kualitatif kedalam bentuk tulisan ilmiah.

\section{HASIL DAN PEMBAHASAN}

\section{Bentuk Penyajian Ritual Pangurason}

\section{Tahap Persiapan}

Menurut nara sumber Marsius Sitohang, pangurason ini berasal dari daerah Pusuk Buhit Batak Toba Kabupaten Samosir. Dalam ritual pangurason ini, pihak yang melakukan upacara mendatangi guru atau sibaso untuk menetukan kapan upacara pangurason tersebut. Seorang dukun atau sibaso merupakan seorang salah satu seorang warga yang mampu untuk menerawang ilmu religi dan dihormati dikampung tersebut, karena dianggap mempunyai sikap yang dapat di panut oleh pihak warga.

Dukun atau sibaso tersebut menentukan hari pelaksanaan ritual berdasarkan dari kalender Batak Toba, atau melalui penerawangan dukun tersebut. Setelah itu dukun atau sibaso menentukan persembahan yang akan disediakan dalam pelaksaan ritual pangurason, setelah hari 
dan persembahan sudah ditentukan, warga tersebut mempersiapkan persembahannya untuk roh halus yang akan dipersembahkan pada ritual pangurason tersebut. Saat upacara berlangsung, tidak ada satu orangpun yang boleh menyentuh atau memakan persembahan tersebut karena dapat melanggar adat. Dipercaya jika warga diam-diam menyentuh atau memakan persembahan tersebut, maka dukun itu akan mengetahuinya pada saat proses upacara itu berlangsung.

\section{Tahap pelaksanaan}

Pada hari upacara ritual pangurason yang sudah ditentukan tersebut, diawali dengan dukun atau sibaso berdoa untuk memulai acara tersebut. Acara ini bisa dimulai pada pagi, siang atau malam hari. Namun lebih banyak melakukan pada malam hari, dikarenakan dianggap pada malam hari lebih tenang agar upacara pangurason berjalan dengan lancar.

Doa yang disampaikan oleh sibaso tidak ada aturan yang sudah tertulis, doa biasanya berkaitan dengan masalah yang terjadi pada warga. Misalnya mengusir roh halus, mengobati penyakit atau kesialan pada warga. Saat sibaso melakukan do'a musik gondangpun dilakukan oleh pemusik dengan tempo musik yang sangat lambat. Gondang juga tidak ditentukan, biasanya gondang yang dimainkan sesuai dengan permintaan sibaso.

Setelah sibaso melakukan doa dan berdiam sejenak, kemudian sibaso akan memanggil seorang warga untuk mengambilkan sawan yang sudah berisikan air dari mata air yang diyakini masyararakat setempat memiliki

manfaat atau khasiat, perasan jeruk purut dan daun beringin. Isi dari sawan tersebut mengandung arti. Air mata air sebagai penyuci, jeruk purut sebagai pembersih kampung yang akan dibersihkan dan daun beringin yang dianggap sebagai sumber kekuatan.

Hal tersebut dipercaya oleh masyarakat Batak Toba itu sendiri. Begitu juga dengan mangkuk putih itu sendiri sebagai simbol kesucian. Pada saat sibaso mengambil sawan tersebut dan memercikkan air dalam sawan itulah yang dikatakan pangurason. Gerakan yang dilakukan sibaso juga tidak memiliki aturan gerak, gerakan yang mengikuti tempo musik dan mengikat hati dari sibaso itu sendiri. Pada umumnya sibaso melakukan somba adat dan somba debata.

\section{Tahap penutup}

Sibaso memercikan air pangurason ke delapan penjuru arah mata angin sambil melkukan gerakan - gerakan embas. Setelah itu semua warga dan Sibaso menortor bersama yang menandakan bahwasannya telah selesai melaksanakan ritual pangurason.

Menurut nara sumber ada dua versi ritual pangurason ada versi yang sampai trance (kesurupan) dan ada yang tidak mengalami trance (kesurupan). Pelaku ritual yang mengalami trance biasanya dipengaruhi gondang atau musik, dan yang tidak mengalami trans biasanya sibaso lebih dapat mengontrol dirinya saat melakukan ritual pangurason.

\section{Ragam gerak pada ritual Pangurason}


Ragam gerak pada ritual Pangurason ada empat ragam yaitu: 1). Somba, 2). SatahiSaoloan, 3). MenolakBala, 4). PapungPasu-pasu.

\section{Musik}

Alat musik yang digunakan untuk mengiringi ritual pangurason disebut dengan gondang, gong dan alat musik Batak Toba. Namun saat ini banyaknya dijumpai pertunjukan ritual pangurason menggunakan $\mathrm{CD}$ atau Kaset yang musiknyapun lebih ke arah modern dengan tempo yang cepat. Sedangkan awalnya ritual ini irama yang dimainkan disesuaikan dengan gerakan penari.

\section{Busana}

Busana yang digunakan dahulunya hanya menggunakan kain ulos yang dipakai sampai mata kaki dan sabuk dipinggang dan menggunakan penutup di atas kepala sortali dengan corak cori khas Batak Toba. Saat ini busana yang digunakan mengarah ke entertain yang memiliki nilai komersil karena mengutamakan keindahan dan daya tarik penonton. Saat ini menggunakan kebaya, rok dan ulos dimodifikasi. Juga didukung dengan hiasaan kepala dengan sanggul dan sunting yang beraneka ragam bentuk.

\section{Properti}

Properti yang digunakan adalah sawan, dalam bahasa Batak sawan itu adalah cawan. Dalam ritual pangurason digunakan tujuh sawan nabolon yang artinya sawan besar atau sawan induk. Dimana dari ketujuh sawan ini salah satu diantaranya memiliki lebih besar sawan yang akan digunakan untuk membersihkan tempat dari roh-roh jahat, itulah yang disebut sibaso bolon.
Dimana sawan tersebut berisikan jeruk purut gunanya untuk mengusir dan membersihkan tempat dari roh-roh jahat.

\section{Transformasi Ritual Pangurason.}

Ritual pangurason telah mengalami transformasi menjadi seni pertunjukan yang pertama sekali memperkasai untuk merubah menjadi seni pertunjukan adalah Tangsi br. Simbolon pada tahun 1953. Ritual pangurason yang bertransformasi menjadi seni pertunjukan yang telah berubah nama menjadi tortor sawan yang terinspirasi dari salah satu media ritual yang digunakan yakni cawan. Tortor cawan karya Tangsi br. Simbolon terdapat dalam Opera Batak.

Setelah tahun 1953 banyak senimanseniman membuat tortor cawan yang juga melakukan transformasi pangurason menjadi tortor cawan antara lain:

Seniman dari luar.

1. Monang Butar-butar dalam sanggar tari Ria agung tahun 1997 dengan judul tortor cawan.

2. Nadra Akbar Manalu dalam sanggar D'Tradisional Performance tahun 2017 dengan judul tortor cawan.

3. Tengku Ari Rahmana dalam Sanggar tari Ai_Ai Dance Company tahun 2016 dengan judul tortor cawan.

4. Ade Junindra dalam Sanggar tari Sumatera Etnis tahun 2006 dengan judul tortor cawan.

Seniman dari dalam.

1. Nurwani tahun 1997 yang berjudul cawan ritual festival tari se-Sumatera dan Kalimantan Barat di Padang Panjang meraih juara 1. 
2. Martozet Tahun 1998 yang berjudul tortor Saoan yang dipertunjukkan di Perancis.

3. Inggit Prasetiawan Tahun 2010 yang berjudul tortor cawan pangurason yang dipertunjukkan di Solo International Performance Art (SIPA).

Seniman dari Samosir.

1. Golda Simarmata tahun 2017 dalam sanggar seni tonggi dengan judul tor tor cawan.

2. Marlita tahun 1990 dalam sanggar si bunga jambu dengan judul Tor-Tor Cawan.

3. Egost Lardy Simanulang tahun 1990 dalam sanggar tari Humbang Nauli dengan judul tortor sawan.

Transformasi yang dilihat dalam penelitian ini adalah karya Golda Simarmata di Samosir dan Togi Sirait di Kota Medan. Dalam penelitian ini dapat dilihat cawan telah mengalami perubahan menjadi seni pertunjukan, maka banyak hadir kreativitas cawan menjadi sebuah karya tari yang dihasilkan seorang seniman yang ada dikota Medan dengan mempunyai makna dan arti tersendiri bagi seorang koreografer. Salah satunya peneliti menganalisis tortor cawan. Terjadinya perubahan kata tersebut memiliki arti dari perubahan bentuk penyajiannya.

Pangurason yang dianggap sakral dengan menggunakan satu cawan memiliki arti pangurason "Menguras yang artinya membersihkan wilayah dari macam hal-hal buruk". Sedangkan pangurason yang mengalami transformasi disebut dengan tor tor cawan. Hal ini penyebutan tortor cawan tidak ada arti, yang berkaitan dengan religi ataupun adat istiadat dari masyarakat Batak Toba. Penyebutan tortor cawan dipandang memiliki nilai jual dan gampang diingat orang atau penonton dalam seni pertunjukan. Dimana tortor artinya tari, cawan adalah mangkuk putih yang digunakan pada saat pertunjukan.

Tortor cawan dari karya Tangsi br. Simbolon diciptakan tahun 1953 menyatakan bahwa pangurason diubah menjadi sebuah tortor cawan menjadi seni pertunjukan yang ada di Opera Batak. Yang bertujuan cawan sebagai seni pertunjukan yang mempunyai nilai akrobatik menurut Tangsi br. Simbolon (nara sumber). Tortor cawan tidak terbatas menjadi satu, tiga , lima, tujuh. Perubahan itu terjadi dari satu ke tujuh cawan, itulah nilai akrobatik dari seni pertunjukannya. Jika seorang penari tidak mampu membawa tujuh maka dianggap seorang penari tersebut tidak bisa menari membawa tortor cawan. Dari situ dapat dilihat bahwasanya tidak terdapat makna religi ataupun makna lain, hanya berkaitan dengan tekhnik seorang penari yang membawa tujuh cawan itu sendiri.

Dalam hal ini penulis melihat transformasi dari pangurason menjadi tortor cawan. Makna dan fungsi yang terlahir dari tortor cawan itu sendiri tergantung dari koreografer yang menciptakannya. Hal itu berkaitan dengan gerak, pola lantai, musik dan kostum yang digunakan oleh koreografer.

\section{PENUTUP}

\section{Kesimpulan}

Kesimpulan yang dapat diambil dari Transformasi pangurason Dari Ritual Keseni Pertunjukan ini, yaitu: 
1. Bentuk ritual pangurason dibagi menjadi tiga tahap yakni tahap persiapan, tahap pelaksaan,dan tahap penutupan.

a. Tahap persiapan

Menurut nara sumber Marsius Sitohang, pangurason ini berasal dari daerah Pusuk Buhit, Batak Toba, Kabupaten Samosir. Dalam ritual pangurason ini, pihak yang melakukan upacara terlebih dahulu mendatangi guru atau sibaso untuk menetukan hari dan tempat upacara pangurason tersebut. Seorang dukun atau disebut juga sibaso merupakan salah satu seorang warga yang mampu untuk menerawang ilmu ghaib dan dihormati dikampung tersebut, karena dianggap mempunyai sikap yang dapat menjadi panutan oleh masyarakat.

b. Tahap pelaksanaan

Setelah menentukan hari dan tempat waktu pelaksanaan ritual pangurason maka guru sibaso melakukan ritual berdoa sebagai awal pembuka dalam ritual ini. Pelaksanaan upacara ritual pangurason ini boleh diadakan pada pagi, siang ataupun malam hari. Namun, pada kenyataannya ritual ini lebih sering dilakukan pada malam hari, dikarenakan dianggap pada malam hari lebih tenang agar upacara pangurason berjalan dengan lancar dan hikmat.

c. Tahap penutupan

Pada tahap penutupan sibaso memercikan air pangurason ke delapan penjuru arah mata angin sambil melakukan gerakan - gerakan embas. Gerakan embas itu adalah gerakan dimana kedua tangan mengayun kedepan. Guru sibaso melakukan perpindahan-perpindahan tempat untuk melakukan ke delapan penjuru arah mata angin. Setelah itu semua warga yang terlibat didalam ritual pangurason ini dan guru sibaso melakukan menortor bersama yang menandakan bahwa ritual pangurason telah selesai dilaksanakan.

2. Tortor Cawan karya Golda Simarmata merupakan tortor Cawan kreasi yang berakar kepada nilai-nilai tradisi. Nilai tradisi yang bertransformasi kedalam bentuk seni pertunjukan.

3. Tortor Cawan transformasi karya Togi Sirait

Pangurason memiliki arti "Menguras yang artinya membersihkan wilayah dari macam hal-hal buruk". Sedangkan pangurason yang mengalami transformasi disebut dengan tortor cawan. Hal ini disebabkan adanya perubahan zaman yang semakin modern dan terkikisnya nilai-nilai tradisi maka masyarakat lebih mudah menginggat dan menyebutkan tortor cawan, dimana tortor artinya tari, dan cawan artinya mangkuk putih yang digunakan pada saat pertunjukan.

\section{Saran}

Berdasarkan hasil penelitian penulis mengajukan beberapa saran yaitu:

1. Dengan adanya penelitian ini diharapkan dapat mengundang minat seniman Batak Toba untuk mendirikan sanggar tari Batak Toba yang berkwalitas 
2. Dengan diadakan penelitian terhadap Transformasi pangurason Dari Ritual Kesenian Pertunjukan di Pangururan Kabupaten Samosir. Agar memberikan perhatian terhadap kelestarian terhadap budaya Batak Toba.

3. Penulis sangat mengharapkan dukungan berbagai instansi terkait agar ikut peduli terhadap perkembangan dan kelestarian budaya Batak Toba.

4. Semoga tulisan ini dapat menjadi acuan tertulis bagi peneliti-peneliti yang lainnya, jika ingin mengkaji pangurason tentu saja diharapkan dari sudut pandang yang berbeda.

\section{DAFTAR PUSTAKA}

Achmadi \& Abu Cholid, 2005. Metodologi Penelitian. Jakarta : Bumi Aksara

Afrianty, 2014. Makna Tor-tor Sibunga Jambu Dalam Gondang Naposa dalam Masyarakat Batak Toba. e Jorunal of Unimed. Jurnal Gesture : Jurnal Seni Tari.

Bangun, 1980. Kebudayaan Batak II. Jakarta : Djambatan

Barthes Roland, 2010. Membedah Mitos-mitos Budaya Masa,Yogyakarta : Jalasutra

By Robert F. Berkhofer \& Jr. A Behaviorial, 1971. Approach To Historical A Nalvy. New york: The Free Press.

Dea Novita Sari, 2015. Tranformasi Tarian Saman Kajian Dalam Konteks Pariwisata di Kota Banda Aceh. e Jorunal of Unimed. Jurnal Gesture : Jurnal Seni Tari.

Hadeli, 2006. Metode Penelitian Pendidikan. Jakarta : Bumi Aksara
Hidayat, 2007. Metode Penelitian. Jakarta : Bumi Aksara.

Irwansyah Harahap, 2016. Hata Ni Debata. Medan : Semai

Irwansyah, 2016. Transformai Gaya Piso Surit di Kabupaten Langkat. $e$ Jorunal of Unimed. Jurnal Gesture : Jurnal Seni Tari.

Koentjaraningrat. 1985 .Ritus Peralihan Di Indonesia. Jakarta : PN Balai Pustaka.

Madjid M. Dien, 2014. Ilmu Sejarah. Jakarta : Prenada Media Group.

Maryeani, 2005. Metode Penelitian Kebudayaan. Jakarta : Bumi Aksara.

Nurwani, 2015. Seni Dalam Perspektif Ilmu Sosial. Medan: Unimed Press

RHD Nugrahaningsih dan Yusnizar Heniwati, 2012. TARI (Identitas dan Resistensi). Medan. Unimed Press.

Rithaony Hutajulu, 2004.Power Gender dan Musik Pada Masyarakat Batak Toba. Jakarta : Jurnal Masyarakat Seni Pertunjukan Indonesia

Sawitri, 2003. Perempuan Dalam Seni Pertunjukan. Jakarta : KSMSPI

Sarma Sirait, 2008. Tor-tor Dalam Upacara Adat Dalam Masyarakat Batak Toba.

Sukardi, 2003. Metodologi Penelitian Pendidikan. Jakarta : Bumi Aksara

Supranto, 2004. Analisis Multivaril : Arti dan Interpretasi. Jakarta : Rineka Cipta.

Suzanne K Langer, 1988. Problems Of Art, terjemahan F. X. Widyanto. Bandung : Akademi Seni Tari Indonesia

Susetyo Bagus, 2007. Handout Materi Pembelajaran ; Kajian Seni Pertunjukan. Semarang. Unnes Press : Pustaka Pelajar. 
Tambunan Betty, 2008. Perkembangan Tor-Tor Batak Tinjauan Terhadap Fungsi Dan Bentuk Penyajiannya.

Taufik Rahzen, 1997. Pertunjukan Perjalanan. Bandung : Masyarakat Seni Pertunjukan Indonesia. 